\title{
A time-efficient reduction of fat mass in 4 days with exercise and caloric restriction
}

\author{
J. A. L. Calbet ${ }^{1,2}$, J. G. Ponce-González ${ }^{1}$, I. Pérez-Suárez ${ }^{1}$, J. de la Calle Herrero ${ }^{1}$, H.-C. Holmberg ${ }^{3}$ \\ ${ }^{1}$ Department of Physical Education, University of Las Palmas de Gran Canaria, Las Palmas de Gran Canaria, Canary Islands, Spain, \\ ${ }^{2}$ Instituto Universitario de Investigaciones Biomédicas y Sanitarias de la Universidad de Las Palmas de Gran Canaria, Las Palmas de \\ Gran Canaria, Canary Islands, Spain, \\ ${ }^{3}$ Department of Health Sciences, Swedish Winter Sports Research Centre, Mid Sweden University, Östersund, Jämtland, Sweden \\ Corresponding author: Jose A. L. Calbet, Departamento de Educación Física, Campus Universitario de Tafira, Las Palmas de Gran \\ Canaria, 35017 Canary Islands, Spain. Tel: +34 928458 896, Fax: +34 928458 867, E-mail: lopezcalbet@gmail.com
}

Accepted for publication 20 January 2014

To determine whether a fast reduction in fat mass can be achieved in 4 days by combining caloric restriction (CR: $3.2 \mathrm{kcal} / \mathrm{kg}$ body weight per day) with exercise (8-h walking + 45-min arm cranking per day) to induce an energy deficit of $\sim 5000 \mathrm{kcal} / \mathrm{day}, 15$ overweight men underwent five experimental phases: pretest, exercise + CR for 4 days (WCR), control diet + reduced exercise for 3 days (DIET), and follow-up 4 weeks (POST1) and 1 year later (POST2). During WCR, the diet consisted solely of whey protein $(n=8)$ or sucrose $(n=7)(0.8 \mathrm{~g} / \mathrm{kg}$ body weight per day). After WCR, DIET, POST1, and POST2, fat mass was reduced by a mean of 2.1, 2.8, 3.8, and $1.9 \mathrm{~kg}(P<0.05)$, with two thirds of this loss from the trunk; and lean mass by $2.8,1.0,0.5$, and $0.4 \mathrm{~kg}$, respectively. After WCR, serum glucose, insulin, homeostatic model assessment, total and low-density lipoprotein cholesterol and triglycerides were reduced, and free fatty acid and cortisol increased. Serum leptin was reduced by $64 \%, 50 \%$, and $33 \%$ following WCR, DIET, and POST1, respectively $(P<0.05)$. The effects were similar in both groups. In conclusion, a clinically relevant reduction in fat mass can be achieved in overweight men in just 4 days by combining prolonged exercise with CR.
The World Health Organization (WHO, 2011) predicts that by 2015 there will be 2.3 billion overweight adults and more than 700 million obese adults worldwide. Obesity can be counteracted by reducing energy intake and/or increasing energy expenditure (EE) to achieve a negative energy balance (EB). Meta-analyses have reported that diet alone produces on the average only a moderate weight loss $(0.5-10.7 \mathrm{~kg})$, whereas combining diet with exercise enhances this weight loss by $0.3-$ $1.1 \mathrm{~kg}$ (Garrow \& Summerbell, 1995; Miller et al., 1997; Shaw et al., 2009). In general, such a reduction is associated with an improved serum lipid profile, lowered blood pressure, and attenuated fasting levels of plasma glucose (Shaw et al., 2009).

A similar or more pronounced reduction in body mass can be achieved much more rapidly (i.e., within 3-10 days) by combining severe caloric restriction (CR) with extensive daily exercise (Carlson \& Fröberg, 1967; Marniemi et al., 1984; Shpilberg et al., 1990). However, in earlier investigations of this nature neither the influence of dietary composition, the impact on body composition, nor medium- and long-term effects (e.g., whether the reduction in weight is maintained or not) were assessed. It has been shown that elevating the amount of protein relative to carbohydrate in weight loss diets lessens the loss of lean mass (LM) and promotes loss of fat (Farnsworth et al., 2003; Krieger et al., 2006).

Accordingly, the primary aim of the present investigation was to characterize the effects of low energy intake (3.2 kcal $/ \mathrm{kg}$ body mass per day) in combination with $9 \mathrm{~h}$ of low-intensity exercise daily on body composition (i.e., regional changes in fat and LM), and serum levels of lipids, glucose, insulin, and leptin in overweight men. In addition, the potential ability of dietary whey protein to preserve LM under these same conditions of pronounced short-term negative EB was examined. A final aim was to assess long-term effects 1 year after the intervention. Our hypotheses were that this regimen would reduce body weight and fat mass markedly, that this effect will to some extent present 12 months later and, that the protein diet would be associated with more loss of fat and less reduction in LM than ingestion of sucrose.

\section{Methods \\ Participants}

The general criteria for inclusion were (a) an age of 18-55 years; (b) stable body weight for at least 3 months prior to the start of the experiments; (c) a body mass index of $\geq 25 \mathrm{~kg} / \mathrm{m}^{2}$; (d) a waist circumference of $>102 \mathrm{~cm}$; and (e) $20 \%-40 \%$ body fat. The 
Calbet et al.

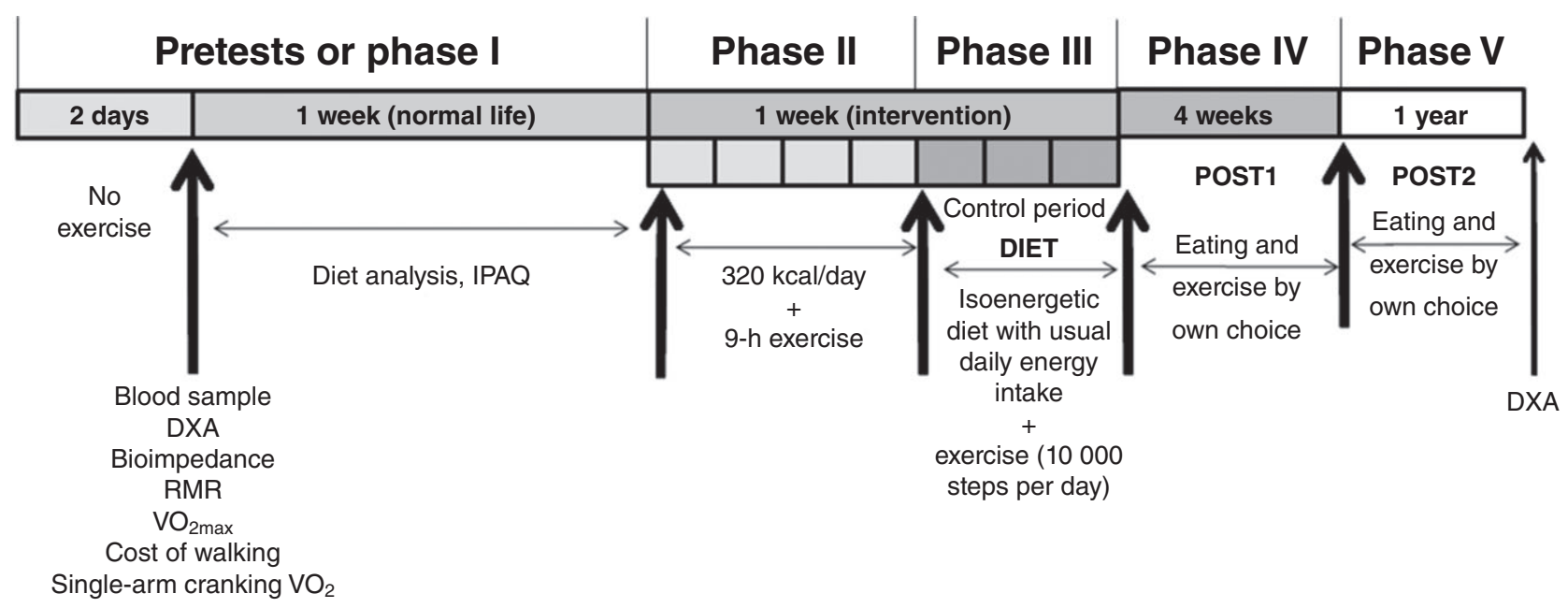

Fig. 1. Schematic illustration of the experimental protocol. RMR, resting metabolic rate; IPAQ, International Physical Activity Questionnaire, DXA, dual-energy x-ray absorptiometry.

exclusion criteria were (a) orthopedic limitations incompatible with prolonged walking or exercise; (b) smoking; and (c) chronic disease of any kind. Of the 16 men recruited initially, one was unable to combine the intervention with his work schedule (Table 1$)$. The 15 remaining participants were assigned randomly to ingest a diet consisting of sucrose $(n=7)$ or whey protein (Whey PRO, Syntrax Nectar, Syntrax Innovations, Scott City, Missouri, USA; $n=8$ ) during the main experimental phase. A study population of this size should reveal any significant difference $\geq 1.5$-fold the coefficient of variation (which was $<10 \%$ in most cases) between the mean values for any given parameter, with a significance level of $P<0.05$ and a statistical power of 0.8 . This study was approved by the Regional Ethical Review Board

Table 1. The pretest physical characteristics, fitness, and energy intake (means \pm SD) of the overweight men who subsequently ingested different diets

\begin{tabular}{|c|c|c|}
\hline & \multicolumn{2}{|l|}{ Diet } \\
\hline & $\begin{array}{l}\text { Sucrose } \\
(n=7)\end{array}$ & $\begin{array}{l}\text { Whey protein } \\
(n=8)\end{array}$ \\
\hline Age (years) & $38.7 \pm 8.2$ & $43.0 \pm 8.0$ \\
\hline Height $(\mathrm{cm})$ & $181.0 \pm 5.5$ & $180.0 \pm 4.2$ \\
\hline Weight (kg) & $98.0 \pm 12.0$ & $100.1 \pm 14.9$ \\
\hline $\mathrm{BMI}\left(\mathrm{kg} / \mathrm{m}^{2}\right)$ & $29.9 \pm 3.1$ & $30.9 \pm 4.2$ \\
\hline Lean mass $(\mathrm{kg})$ & $63.1 \pm 3.1$ & $65.4 \pm 6.0$ \\
\hline Fat mass $(\mathrm{kg})$ & $31.5 \pm 9.1$ & $31.4 \pm 9.2$ \\
\hline Body fat $(\%)$ & $31.6 \pm 5.3$ & $30.9 \pm 4.1$ \\
\hline RMR (kcal/day) & $1780 \pm 272$ & $1970 \pm 348$ \\
\hline $\mathrm{VO}_{2 \max }(\mathrm{L} / \mathrm{min})$ & $3.8 \pm 0.3$ & $3.9 \pm 0.3$ \\
\hline $\mathrm{VO}_{2 \max }(\mathrm{mL} / \mathrm{kg} / \mathrm{min})$ & $38.8 \pm 6.0$ & $39.7 \pm 5.5$ \\
\hline $\mathrm{VO}_{2 \max }(\mathrm{mL} / \mathrm{kg}$ lean mass per min) & $59.6 \pm 6.4$ & $60.2 \pm 6.1$ \\
\hline Daily energy intake (kcal) & $2256 \pm 513$ & $2086 \pm 489$ \\
\hline Carbohydrate intake (g/day) & $211.5 \pm 59.4$ & $212.3 \pm 59.8$ \\
\hline Fat intake (g/day) & $92.0 \pm 14.6$ & $80.2 \pm 21.7$ \\
\hline Protein intake (g/day) & $99.8 \pm 29.6$ & $83.7 \pm 18.0$ \\
\hline Alcohol intake (g/day) & $26.1 \pm 17.4$ & $25.7 \pm 14.2$ \\
\hline Physical activity (IPAQ) kcal/day & $612 \pm 315$ & $601 \pm 289$ \\
\hline Systolic blood pressure (mmHg) & $135 \pm 7$ & $132 \pm 13$ \\
\hline Diastolic blood pressure (mmHg) & $88 \pm 5$ & $89 \pm 9$ \\
\hline
\end{tabular}

BMI, body mass index; IPAQ, International Physical Activity Questionnaire; RMR, resting metabolic rate; $S D$, standard deviation. of Umeå University (Umeå, Sweden), as well as the Ethical Committee of the University of Las Palmas de Gran Canaria (Canary Islands, Spain). The participants provided their written consent after being informed about potential risks and benefits.

\section{Experimental protocol}

The experimental protocol was divided into five different phases: I (pretest), II [walking and arm-cranking exercise + caloric restriction (WCR), lasting 4 days], III [control diet + reduced exercise (DIET), lasting 3 days], IV (4 weeks after the end of WCR), and V (1 year later) (Fig. 1). During phase I and at the end of phases II, III, and IV, body composition (Lunar iDXA, GE Healthcare, Madison, Wisconsin, USA; and Bioimpedance, InBody720, Biospace Co., Ltd, Seoul, Korea) and $\mathrm{VO}_{2 \max }$ (on a cycle ergometer) were assessed. In addition, during phases I, II, and III, $30 \mathrm{~mL}$ of blood samples was drawn (in the supine position), following a 12-h overnight fast. In phase I, blood samples were obtained on two occasions, 1 week apart. During phase V, only body composition was characterized.

Phase II started with a 12-h overnight fast, after which a blood sample was taken. The subjects performed $45 \mathrm{~min}$ of one-arm cranking exercise (at $15 \%$ maximal intensity), followed by $8 \mathrm{~h}$ of walking at $4.5 \mathrm{~km} / \mathrm{h}(35 \mathrm{~km} /$ day) (at temperatures ranging from 2.9 to $\left.10.2^{\circ} \mathrm{C}\right)$. On each day of this phase, the participants ingested (in a double-blinded fashion) either sucrose or whey protein $[0.8 \mathrm{~g} / \mathrm{kg}$ body weight (Syntrax Innovations)], both dissolved in $1.5 \mathrm{~L}$ of water containing minerals, as their only nutrients, providing an overall energy intake of $3.2 \mathrm{kcal} / \mathrm{kg}$ body weight per day. The solution of whey protein also contained $\mathrm{Na}^{+}$ (308 $\mathrm{mg} / \mathrm{L})$ and $\mathrm{K}^{+}(370 \mathrm{mg} / \mathrm{L})$, as did the sucrose solution $\left(160 \mathrm{mg} / \mathrm{L}\right.$ of $\mathrm{Na}^{+}$and $100 \mathrm{mg} / \mathrm{L}$ of $\mathrm{K}^{+}$). The subjects drank $0.5 \mathrm{~L}$ in the morning (just before arm cranking), again at midday and at 20:00 h. In addition, both groups were allowed to drink a hypotonic rehydrating solution containing $\mathrm{Na}^{+}(160 \mathrm{mg} / \mathrm{L}), \mathrm{Cl}^{-}$ $(200 \mathrm{mg} / \mathrm{L}), \mathrm{K}^{+}(100 \mathrm{mg} / \mathrm{L})$, citrate $(700 \mathrm{mg} / \mathrm{L})$, and sucrose ( $3 \mathrm{~g} / \mathrm{L})$ ad libitum.

During phase III, the participants received a standardized meal containing their normal daily intake of energy (as assessed during the pretest by weighing all food ingested during a 7-day period) and were not allowed to walk more than 10000 steps per day. The purpose of this phase was to allow replenishment of water and stabilization of body weight. At the end of this phase, they were 
counseled about changes in diet and other aspects of their lifestyle required to maintain their new body composition and allowed to decide themselves whether to follow this advice or not. Four weeks and again 1 year after the end of phase III, the subjects were examined to determine if they had been able to maintain their new body composition and, on the first of these occasions, their hydration status was also checked. Each testing session started with the determination of body composition and resting metabolic rate (RMR).

Assessment of physical activity, nutrition, and body composition

The short version of the International Physical Activity Questionnaire was used to assess daily EE related to physical activity (Craig et al., 2003; Serrano-Sanchez et al., 2010). During phase I, a 7-day dietary diary was kept by each participant and their food items analyzed (Dietist XP, Kost och Näringsdata, Bromma, Sweden). During phase III, they were provided a diet of similar composition and the same energy as that recorded during phase I, and the weight of the food they ingested was determined. Energy intake was also calculated employing Dietist XP (Kost och Näringsdata $A B$ ). During this phase, the sucrose group ingested $2256 \pm 513$ and the Whey PRO group $2086 \pm 450 \mathrm{kcal} /$ day [means \pm standard deviation (SD)] (Table 1).

In the morning following a 12-h overnight fast, body composition was determined by bioimpedance (Gibson et al., 2008), and dual-energy x-ray absorptiometry (DXA) as reported elsewhere (Calbet et al., 2001; Perez-Gomez et al., 2008). For analysis of bioimpedance, the participants were requested to stand upright and to grasp the handles of the InBody720 to make contact with a total of eight electrodes (two for each foot and hand). LM as assessed with the iDXA was defined as LM = total tissue mass - fat mass bone mineral content.

\section{RMR, submaximal $\mathrm{VO}_{2}$, and $\mathrm{VO}_{2 \max }$}

RMR, submaximal $\mathrm{VO}_{2}$, and $\mathrm{VO}_{2 \max }$ were assessed employing a metabolic cart (Jaeger Oxycon Pro, Viasys Healthcare, Hoechberg, Germany), calibrated with $16.0 \% \mathrm{O}_{2}$ and $4.0 \% \mathrm{CO}_{2}$ (Air Liquide, Kungsängen, Sweden), at low, medium, and high flow rates with 3 L of air syringe (Hans Rudolph, Inc, Kansas City, Missouri, USA), in accordance with the recommendations of the manufacturer. Ambient conditions were monitored with an external apparatus (Vaisala PTU200, Vaisala Oyj, Helsinki, Finland). The highest $\mathrm{VO}_{2}$ value during any 20-s interval of an incremental test on the cycle ergometer (Monark 839E; Ergomedic, Vansbro, Sweden) was designated as the $\mathrm{VO}_{2 \max }$. RMR was determined following $10 \mathrm{~min}$ of steady ventilation and $\mathrm{VO}_{2}$ in the supine position. The submaximal $\mathrm{VO}_{2}$ during walking and arm cranking was utilized to estimate EE during exercise.

\section{EE during exercise and the expected rate of fat loss during phase II}

Daily EE during phase II was calculated on the basis of the duration and mean speed of walking (Forerunner 305, Garmin, Olathe, Kansas, USA). The energy cost of walking was measured in phase I during horizontal walking on a treadmill at 3.5 and $6.0 \mathrm{~km} / \mathrm{h}$ (averaging the last $2 \mathrm{~min}$ of each 6-min bout) (RL 4000, Rodby Innovation AB, Vänge, Sweden). The energy cost of singlearm cranking was determined by an incremental test with the axis of the arm crank at shoulder level, a frequency of $1 \mathrm{~Hz}$, and an initial load of $10 \mathrm{~W}$, which was increased by $10 \mathrm{~W}$ every third minute. The last minute at each load was used to obtain the $\mathrm{VO}_{2}$. The corresponding EE for both forms of exercise was calculated from the $\mathrm{VO}_{2}$ and $\mathrm{VCO}_{2}$ (Frayn, 1983). The energy cost of walking on the terrain was calculated employing the equation developed by Pandolf and coworkers (Givoni \& Goldman, 1971; Pandolf et al., 1977), taking into account the characteristics of the terrain (terrain factor $=1.2$ ), which was further increased by $2 \%$ to account for the load being carried (a small backpack with extra clothing and approximately $3 \mathrm{~L}$ of water).

The EB was determined as EB = energy intake $-\mathrm{EE}$. The daily $\mathrm{EE}$ was calculated as the measured RMR + the thermodynamic effect of food (10\% of the ingested energy) + the EE during walking $(\mathrm{EEW})+$ the EE during arm cranking $($ EEAC) + EE due to miscellaneous physical activities (MPAs) + estimated oxygen debt (assumed to represent $10 \%$ of EE due to physical activities (Bahr \& Sejersted, 1991), i.e., $1.1 \times(\mathrm{EEW}+\mathrm{EEAC}+\mathrm{MPA})$. The MPA was calculated as MPA $=(\mathrm{RMR} \times 100 \times 0.4) \times$ time awake and sedentary/total time awake (i.e., $341 \pm 58 \mathrm{kcal} /$ day). This assessment assumes a physical activity level of 1.4 for sedentary subjects (Westerterp, 2013), a total of $16 \mathrm{~h}$ awake and $7.15 \mathrm{~min}$ awake and sedentary.

The EB was also estimated from the changes in the energy content of the body using the changes in body composition, assigning energy values of 39.4 and $3.7 \mathrm{MJ} / \mathrm{kg}$ to fat and $\mathrm{LM}$, respectively (Elia et al., 2003; Guerra et al., 2014).

\section{Biochemical and hormonal analyses}

After a 12-h overnight fast, $20 \mathrm{~mL}$ of blood samples was drawn from an antecubital vein directly into Vacutainer tubes (REF: 368499; 368498; BD Vacutainer, Stockholm, Sweden). To obtain plasma, some samples were collected in tubes containing ethylenediaminetetraacetic acid and centrifuged for $5 \mathrm{~min}$ at 4000 $\mathrm{rpm}$ and $4{ }^{\circ} \mathrm{C}$. To prepare serum, other samples were centrifuged for $10 \mathrm{~min}$ at $4000 \mathrm{rpm}$ and $4{ }^{\circ} \mathrm{C}$. All plasma and serum samples were stored at $-80^{\circ} \mathrm{C}$ until analyzed.

The serum concentration of glucose was measured by the hexokinase procedure utilizing ABX Pentra kits (Horiba Medical, Montpellier, France). Non-esterified free fatty acids, total cholesterol, high-density lipoprotein (HDL) cholesterol and triglycerides were determined enzymatically with kits from Wako Chemicals (Neuss, Germany) and Instrumentation Laboratory (Izasa, Barcelona, Spain).

Serum insulin was quantified by an electrochemiluminescence immunoassay performed with reagent kits and a Modular Analytics Analyzer E170 (Roche Diagnostics SL, Barcelona, Spain). In this case, the sensitivity was $0.2 \mu \mathrm{U} / \mathrm{mL}$, and the corresponding intra- and inter-assay coefficients of variation were $2.0 \%$ and $2.6 \%$, respectively.

Serum leptin was determined by the enzyme-linked immunosorbent assay (ELx800 Universal Microplate Reader, Bio-Tek Instruments, Inc, Winooski, Vermont, USA), employing reagent kits from Linco Research (\#EZHL-80SK, St Charles, Missouri, USA). In this case, the sensitivity was $0.05 \mathrm{ng} / \mathrm{mL}$ and the intraand inter-assay coefficients of variation were $3.8 \%$ and $4.4 \%$, respectively.

Cortisol was measured with a chemiluminescent enzyme immunoassay (Immulite 2000 Cortisol, Ref. L2KCO2; Siemens AG, Munich, Germany) exhibiting a sensitivity of $0.20 \mu \mathrm{g} / \mathrm{dL}$, and intra- and inter-assay coefficients of variation of $6.1 \%$ and $8.2 \%$, respectively. The formula developed by Friedewald et al. (1972) was applied to calculate plasma levels of low-density lipoprotein cholesterol (LDL cholesterol).

\section{Assessment of insulin resistance}

The degree of insulin resistance was estimated by homeostasis model assessment (HOMA) (Matthews et al., 1985). In brief, the 


\section{Calbet et al.}

HOMA index was calculated as the fasting plasma concentration of insulin $(\mu \mathrm{U} / \mathrm{mL}) \times$ the corresponding concentration of glucose $(\mathrm{mmol} / \mathrm{L}) / 22.5$.

\section{Statistical analyses}

Variables were checked for normal distribution with the ShapiroWilk test and when necessary, logarithmically transformed data were analyzed. A repeated-measures analysis of variance with time and the two different diets (sucrose vs whey protein) was applied to analyze the mean responses. When a significant effect of diet or interaction between diet and time was indicated, pairwise comparisons at specific time points were adjusted for multiple comparisons with the Holm-Bonferroni procedure. The relationship between variables was examined by linear regression. Unless otherwise stated, the values reported are means \pm SDs and a $P$-value $\leq 0.05$ was considered statistically significant. All statistical analyses were performed using SPSS v.15.0 for Windows (SPSS, Inc, Chicago, Illinois, USA).

\section{Results}

As shown in Table 1, the baseline (pretest) characteristics of both groups were similar.

\section{Body composition}

Following 4 days of $\mathrm{CR}$ in combination with exercise, total body mass in both dietary groups was reduced by an average of $4.9 \mathrm{~kg}$ and this reduction persisted during all subsequent phases $(P<0.05)$ (Table 2) (being 3.9, 4.4, and $2.4 \mathrm{~kg}$ lower than the pretest value after phases II, $\mathrm{IV}$, and $\mathrm{V}$, respectively), with no significant difference between groups.

Whole-body fat mass (DXA data) was reduced by 2.1, 2.8, 3.8, and $1.9 \mathrm{~kg}$ following phases II, III, IV, and V, respectively (Fig. 2(a)), with similar changes in percentage of body fat (Table 2). Whole-body LM was reduced by $2.8,1.0,0.5$, and $0.4 \mathrm{~kg}$ following phases II, III, IV, and $\mathrm{V}$, respectively (Table 2). Because there were no significant differences between groups in these respects, their values have been pooled in Fig. 2. During phase II, the EB from the estimated EE was $-4873 \pm 952 \mathrm{kcal} /$ day, which was similar to the value obtained from the body composition changes $(-5535 \pm 2083 \mathrm{kcal} / \mathrm{day}$, $P=0.24$; without correction for changes in body water).

The mass of trunk fat was reduced by 1.6, 2.1, 2.8, and $1.1 \mathrm{~kg}$ following phases II, III, IV, and V, respectively (Fig. 2(b)). The amount of fat loss from the extremities was smaller (Fig. 2(b) and Table 3), the corresponding values being $0.5,0.7,1.1$, and $0.8 \mathrm{~kg}$, respectively (Fig. 2(c)). Again, these changes were similar in both dietary groups.

Whole-body water (bioimpedance) was reduced by $3.1 \pm 1.3 \mathrm{~L}(P<0.05)$ following phase II, reflecting $1.8 \pm 0.9$ and $1.3 \pm 0.5 \mathrm{~L}$ reductions in intracellular and extracellular water, respectively $(P<0.05)$, with no significant effect of diet. After 3 days of normal diet + reduced exercise (phase III), body water recovered.

\section{Waist circumference}

Waist circumference was reduced by $4.5 \pm 2.8 \mathrm{~cm}$ following phase II and remained diminished by $5.6 \pm 3.5 \mathrm{~cm}$ after phase III $(P<0.05)$. However, the most pronounced lowering $(7.0 \pm 4.3 \mathrm{~cm})$ was observed after phase IV. Again, the nature of the diet ingested during CR exerted no impact.

\section{Biochemical and hormonal responses}

The biochemical and hormonal responses are depicted in Table 4. The two determinations performed during phase I gave similar values, and the average of these two was taken as baseline. CR in combination with exercise (phase II) lowered serum levels of glucose, insulin, and HOMA by $15 \%, 49 \%$, and $57 \%$, respectively $(P<0.05)$. Three days later, after consuming a control diet with limited exercise (phase III), the levels of insulin and HOMA were still reduced by $32 \%$ and $37 \%$, respectively $(P<0.05)$. In comparison with the baseline values, plasma triglycerides fell by $45 \%$ and $33 \%$ after phases II and III, respectively $(P<0.05)$; serum levels of FFA were 2.9-fold higher after phase II; the total cholesterol and LDL cholesterol levels were attenuated by $17 \%$ and $16 \%$, respectively, after phase III $(P<0.05)$; and HDL cholesterol rose by $25 \%$ after phase II, returning to values similar to baseline after phase III. Four weeks after the intervention (phase IV), when the subjects had $3.8 \mathrm{~kg}$ less fat mass than before the experiment, most of the biochemical values determined had returned to baseline, with the exception of the persistent reduction in total $(-7 \%)$ and LDL serum cholesterol $(-6 \%)(P<0.05)$.

Compared with the corresponding baseline values, the serum levels of cortisol rose by $16 \%$ following phase II, but had returned to the original level after phase III. Serum leptin concentration was lowered $64 \%, 50 \%$, and $33 \%$, following phases II, III, and IV, respectively. No significant between-group differences in biochemical and hormonal responses were observed.

\section{Discussion}

The present investigation reveals that whole-body fat mass can be reduced by $\sim 3 \mathrm{~kg}$ with a 4-day intervention combining a reduction of energy intake (to barely $10 \%$ of the habitual level) and $9 \mathrm{~h}$ of low-intensity exercise per day. Interestingly, most of this reduction was accounted for by loss of adipose depots in the trunk, with an accompanying marked diminution of the waist circumference. Moreover, despite no specific request for lifestyle changes, subjects lost an additional kilogram of fat during the 4 weeks after the intervention (phase IV), giving a total fat loss of $3.8 \mathrm{~kg}$ (of which $2.8 \mathrm{~kg}$ was from the trunk).

This outcome is better than several interventions combining low-calorie diets and exercise lasting from 12 


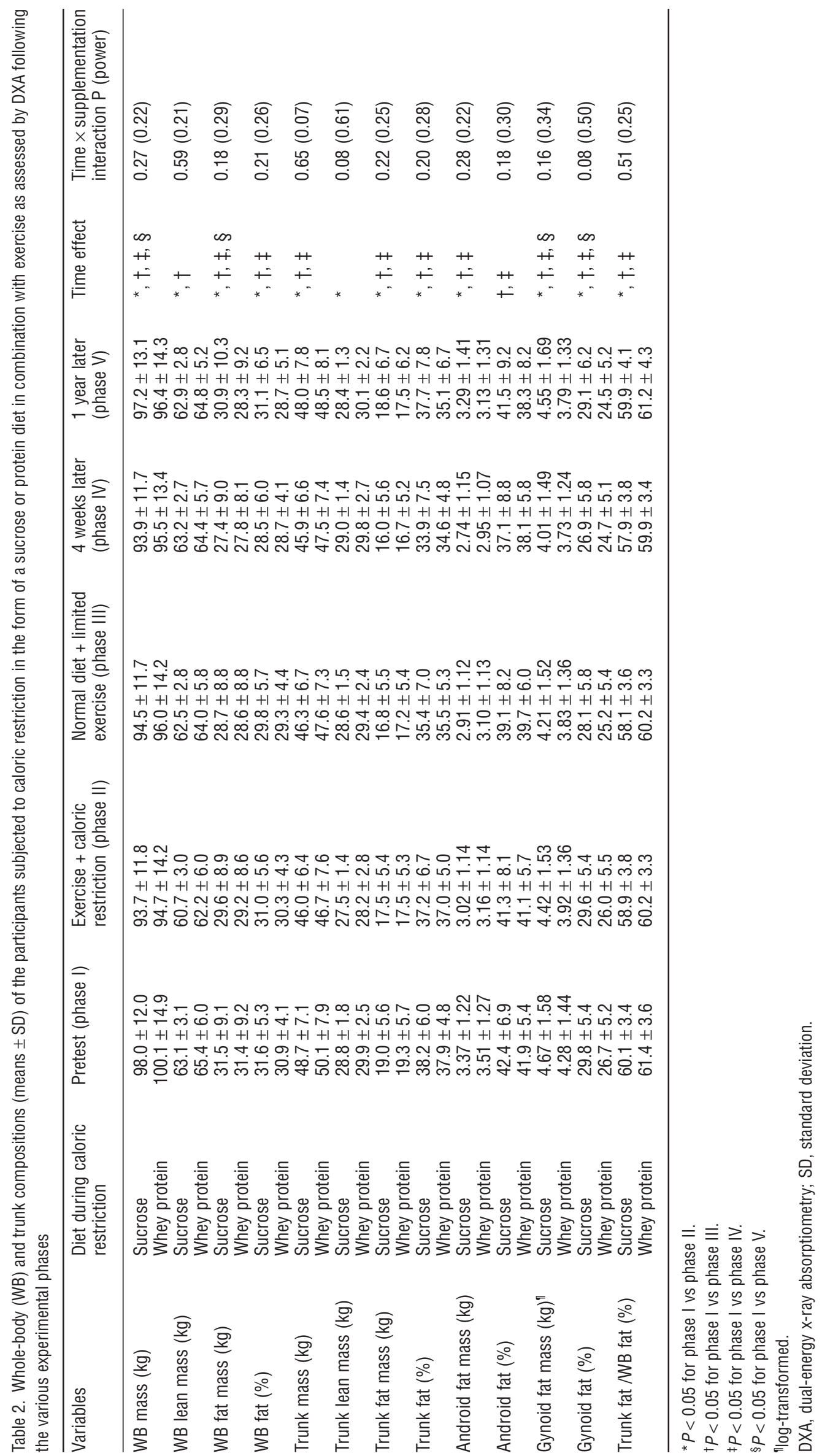


Calbet et al.
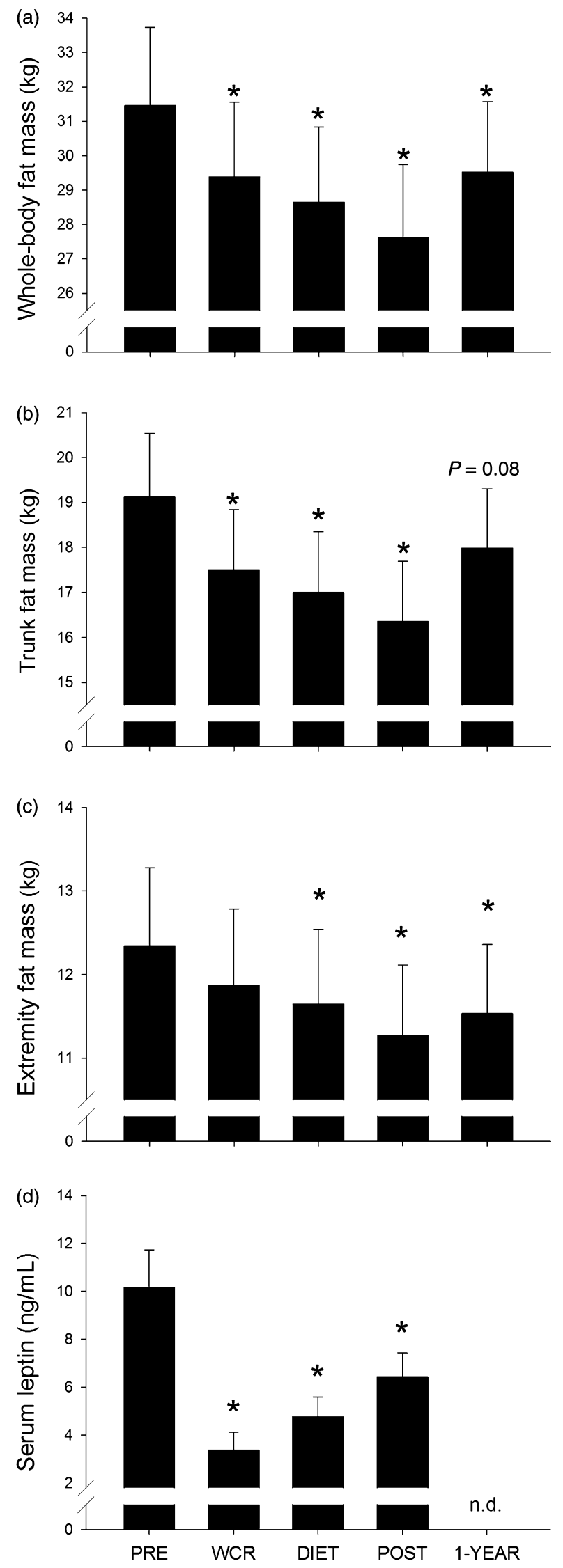

Fig. 2. Assessment of changes in whole-body (a), trunk (b), and extremities (c) fat mass by dual-energy x-ray absorptiometry immediately after 4 days of exercise and caloric restriction (WCR), followed by 3 days of normal diet and limited exercise (DIET), 4 weeks later (POST), and 1 year after the intervention (1-YEAR). In (d), the serum leptin concentrations associated with these same phases are documented (n.d., not determined; PRE, baseline values). Because there were no statistically significant differences between the dietary groups, their values have been combined here, so that $n=15$ in all cases. The values presented are means \pm standard errors of the mean. $* P<0.05$ compared with PRE.

weeks to 1 year (Garrow \& Summerbell, 1995; Shaw et al., 2009), as well as in the largest randomized control trial for the response to 8-month resistance training, aerobic training, or combined aerobic and resistance training (Willis et al., 2012). Furthermore, the mean fat loss here is greater than that achieved by administering agonists of glucagon-like peptide- 1 receptor for at least 20 weeks (which gave a weighted mean loss of $2.9 \mathrm{~kg}$ in 21 trials involving 6411 participants) (Vilsboll et al., 2012). Interestingly, 1 year after the intervention the mass of whole-body fat was still $1.9 \mathrm{~kg}$ below the preintervention level, i.e., the subjects had regained only $50 \%$ of the fat they lost. This is better than reported in meta-analyses on weight regain following adherence to weight loss diets (Anderson et al., 2001; Kraschnewski et al., 2010).

In the present study, trunk fat (a valid surrogate for visceral fat; Doyon et al., 2011) was $2.8 \mathrm{~kg}$ lower 4 weeks after the intervention. This finding is consistent with reports on preferential reduction of visceral fat with modest weight loss achieved by consuming very lowcalorie diets (Chaston \& Dixon, 2008). Visceral fat augments blood levels of lipids and causes low-grade inflammation, endothelial dysfunction, and insulin resistance, thereby elevating the risk for cardiovascular disease (Despres et al., 2001; Nieves et al., 2003; Pou et al., 2007; Takata et al., 2007; Cartier et al., 2008; Fair \& Montgomery, 2009; Kerr et al., 2011). This preferential reduction of fat in the trunk might have been facilitated by exercise-induced activation of lipolysis in this region, as well as by the elevation in serum cortisol and concomitant decrease in circulating levels of insulin following 4 days of exercise and CR (Gravholt et al., 2002; Drapeau et al., 2003; Djurhuus et al., 2004; McMurray \& Hackney, 2005).

Improvements in plasma levels of cholesterol, HDL cholesterol, and cholesterol/HDL cholesterol ratio, as well as in insulin sensitivity and resting systolic and diastolic blood pressure have been reported even after only a 5\%-10\% reduction in body mass (Ross et al., 2000; Brochu et al., 2003). This was also observed in the present investigation, where the levels of total cholesterol, LDL cholesterol, and triglycerides in the serum were lowered immediately after the 4-day period of exercise $+\mathrm{CR}$. However, after the subsequent 3-day period 
Fast and efficient reduction of fat mass

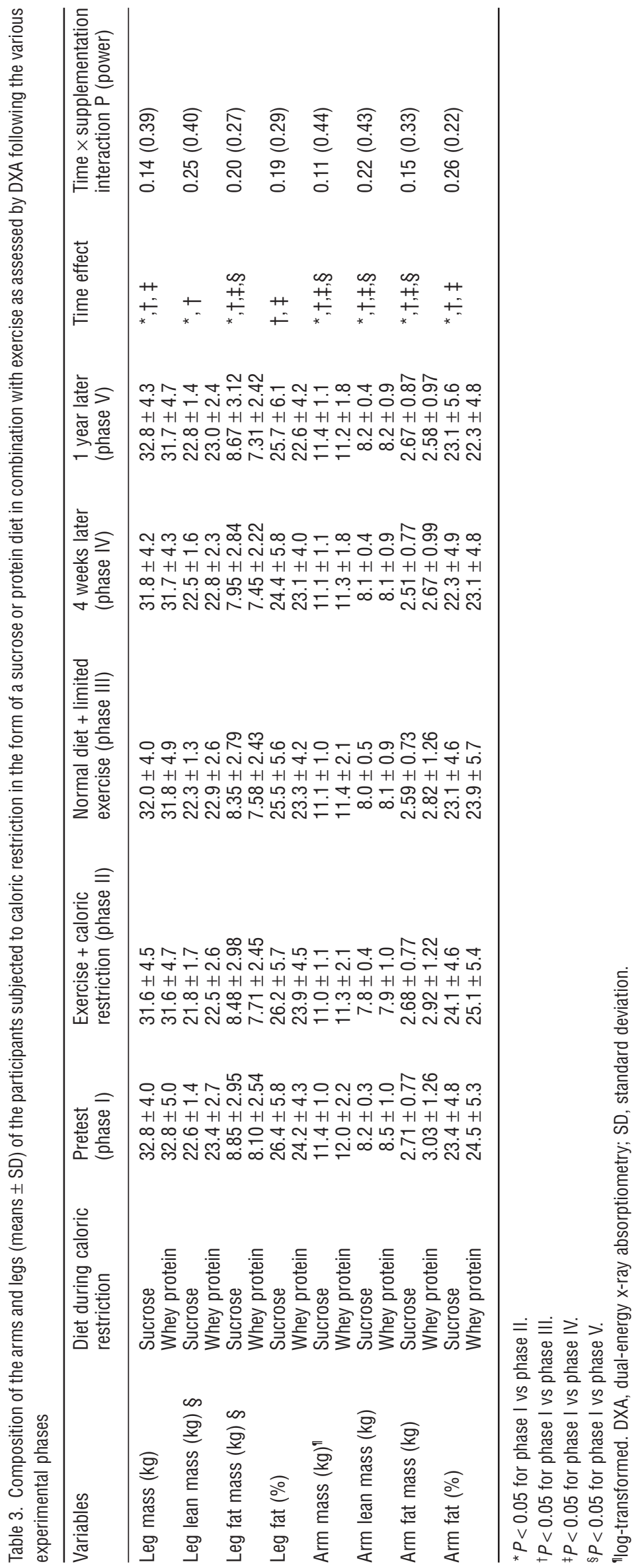


Calbet et al.

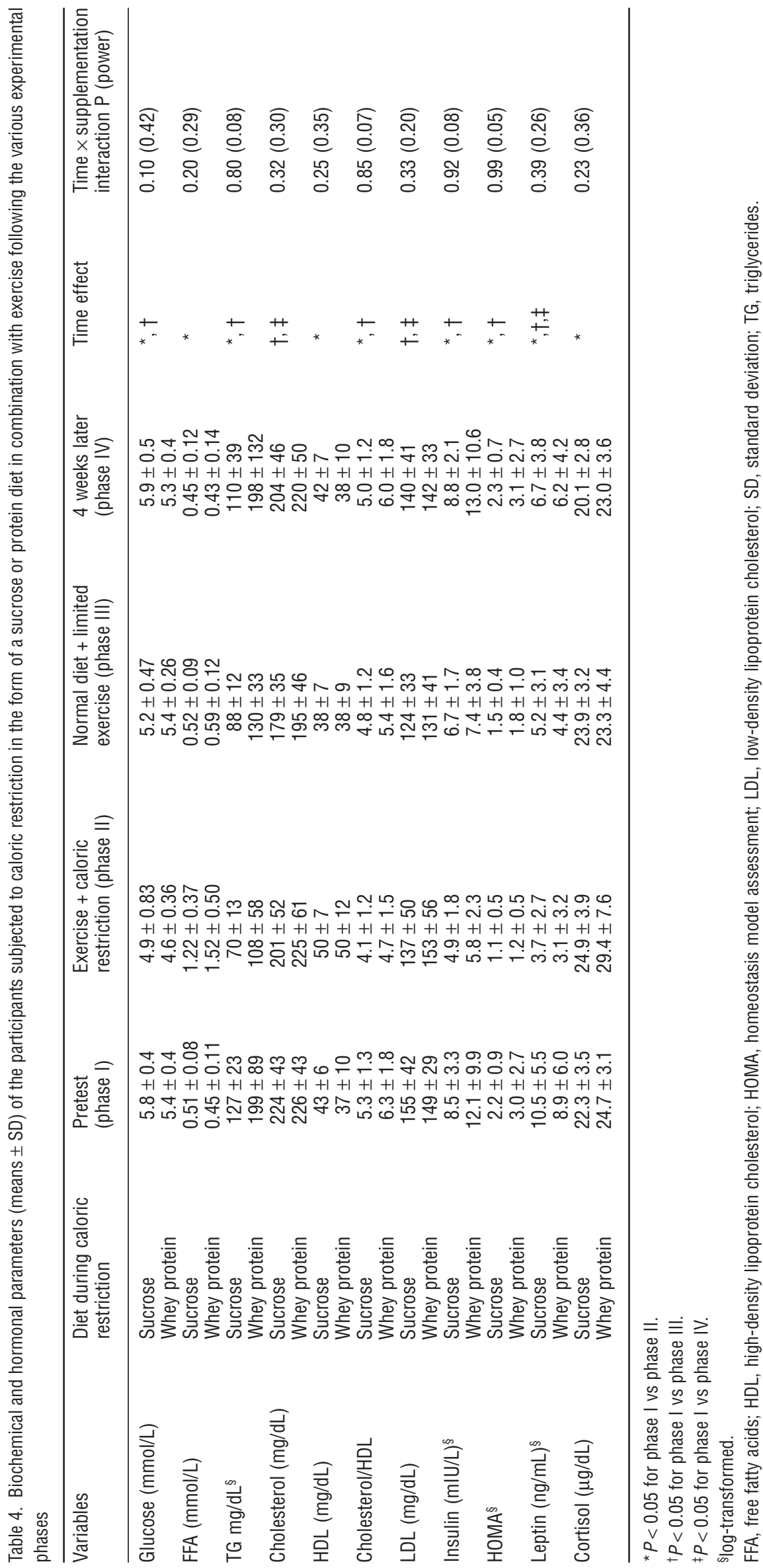


of normal diet and limited exercise, the level of HLD cholesterol had returned to the baseline value, even though the $0.7 \mathrm{~kg}$ additional reduction in fat mass during this same period (phase III) indicated that the subjects still had a markedly negative EB.

Four weeks after the intervention, when wholebody fat was $3.8 \mathrm{~kg}$ below the starting level, the serum levels of glucose, insulin, triglycerides, FFA, and HDL cholesterol were similar to the corresponding baseline values, whereas the serum concentrations of LDL cholesterol remained slightly $(6 \%-7 \%)$ reduced. These findings suggest that physical activity and/or an energy deficit may have exerted a more pronounced impact on the lipid profile than did the changes in fat mass. This subsequent worsening of the lipid profile was accompanied by a rising serum level of leptin, perhaps reflecting progressive development of leptin resistance.

In disagreement with our hypothesis, the extent and regional distribution of fat loss was similar in the groups ingesting either sucrose or whey protein only. In previous dietary studies, elevating the relative amount of protein in the diet resulted in more pronounced fat loss and better preservation of LM (Farnsworth et al., 2003; Krieger et al., 2006). Two major differences between the present and previous investigations are the number of kilocalories ingested daily and the magnitude of the energy deficit sustained on each day of exercise.

Whey protein is rich in branched-chain amino acids, efficiently stimulates protein synthesis, and attenuates protein breakdown in humans (Pennings et al., 2011; Phillips, 2011). The total daily intake of whey protein $(0.8 \mathrm{~g} / \mathrm{kg}$ body weight $)$ employed here exceeded by far the quantity $(20 \mathrm{~g})$ required to achieve maximal stimulation of protein synthesis in both rested and exercised muscle (Tang et al., 2009; Breen et al., 2011; Yang et al., 2012). Since after adjusting for the reduction in extracellular body water our subjects lost approximately $380 \mathrm{~g}$ of LM per day during phase II, the amount of protein ingested should have been sufficient to avoid these losses. However, our findings indicate that under such severe energy deficit, whey protein has no detectable sparing effect on LM and, consequently, the group receiving whey protein lost the same amount of LM as the group receiving only sucrose. It remains to be determined whether better preservation of LM could be achieved with a higher intake or other types of proteins (Agus et al., 2000; Carbone et al., 2012). We cannot rule out the possibility that protein ingestion might exert positive effects during a longer intervention or with a more moderate energy deficit (Pasiakos et al., 2013).

Other factors may have prevented the stimulation of protein synthesis and/or attenuation of protein breakdown expected with our protein diet. For example, because the amount of energy ingested was so much less than $\mathrm{EE}$, in the absence of dietary carbohydrate and the presence of considerable catabolic stress most of this protein may have undergone oxidation or ketogenesis to maintain hepatic gluconeogenesis (Cahill, 2006).

\section{Limitations}

The present proof-of-concept study does not propose an alternative treatment for obesity. Although most of the subjects tolerated the intervention relatively well, all complained of muscle and joint pain, individuals who are less strongly motivated would probably not tolerate this type of intervention. The observation that body weight remained significantly reduced 1 year later could reflect a change in lifestyle, which was not assessed here. Although the analysis of EB was based on changes in body composition evaluated with DXA, this agreed relatively well with the energy deficit calculated from the daily EE. Finally, although we aimed at matching energy intake with EE during phase III, the subjects lost fat mass during this period, indicating a negative EB. The latter might have been caused by underreporting of food intake when measured during phase I.

In conclusion, we have demonstrated that a clinically relevant reduction in fat mass, mostly from the trunk, can be achieved in overweight men by 4 days of extensive exercise in combination with severe CR. This effect is at least as large and sustainable as those obtained employing other regimens designed to reduce body weight. Our results also indicate that when the energy deficit is very high, ingestion of the recommended dietary requirements for protein $(0.8 \mathrm{~g} / \mathrm{kg}$ body weight per day) does not prevent loss of body protein any more effectively than the same amount of energy provided in the form of sucrose.

\section{Perspectives}

Prolonged walking for several hours on consecutive days in combination with a very low-calorie diet can reduce fat mass in overweight adults by $0.5 \mathrm{~kg} / \mathrm{day}$. The main advantage of this approach is that fat is lost primarily from the trunk and in a relatively short time. This intervention is accompanied by improvements in the blood lipid profile and a rapid and sustained reduction in the serum level of leptin, indicating attenuated leptin resistance that may help to maintain body weight. The LM also lost accounts for only less than $15 \%$ of the entire loss in mass. For these reasons, it would be worthwhile to determine whether this weight loss program could be repeated periodically to achieve greater reduction in fat mass during a much shorter period of time than with other programs. 


\section{Calbet et al.}

Key words: Obesity, hypocaloric diet, whey protein, sucrose, walking.

\section{Acknowledgements}

This study was supported financially by grants from the Ministerio de Educación y Ciencia (DEP2010-21866, and FEDER), Proyecto Estructurante de la ULPGC: ULPAPD-08/01-4, and Östersund municipality. We offer special thanks to José Navarro de Tuero for his excellent technical assistance.

\section{Authors contributions}

The authors' contributions were as follows: J. G. P.-G., H.-C. H., and J. A. L. C. designed and conducted this research, analyzed the data, and wrote the manuscript; H.-C. H. and J. A. L. C. had primary responsibility for the final version; J. D. C. H. and I. P.-S. analyzed the data. All authors read and approved the final manuscript.

\section{References}

Agus MS, Swain JF, Larson CL, Eckert EA, Ludwig DS. Dietary composition and physiologic adaptations to energy restriction. Am J Clin Nutr 2000: 71: 901-907.

Anderson JW, Konz EC, Frederich RC, Wood CL. Long-term weight-loss maintenance: a meta-analysis of US studies. Am J Clin Nutr 2001: 74: 579-584.

Bahr R, Sejersted OM. Effect of feeding and fasting on excess postexercise oxygen consumption. J Appl Physiol 1991: 71: 2088-2093.

Breen L, Philp A, Witard OC, Jackman SR, Selby A, Smith K, Baar K, Tipton $\mathrm{KD}$. The influence of carbohydrate-protein co-ingestion following endurance exercise on myofibrillar and mitochondrial protein synthesis. J Physiol 2011: 589: 4011-4025.

Brochu M, Tchernof A, Turner AN, Ades PA, Poehlman ET. Is there a threshold of visceral fat loss that improves the metabolic profile in obese postmenopausal women? Metabolism 2003: 52: 599-604.

Cahill GF Jr. Fuel metabolism in starvation. Annu Rev Nutr 2006: 26: $1-22$.

Calbet JA, Dorado C, Diaz-Herrera P, Rodriguez-Rodriguez LP. High femoral bone mineral content and density in male football (soccer) players. Med Sci Sports Exerc 2001: 33: 1682-1687.

Carbone JW, McClung JP, Pasiakos SM. Skeletal muscle responses to negative energy balance: effects of dietary protein. Adv Nutr 2012: 3: 119-126.

Carlson LA, Fröberg SO. Blood lipid and glucose levels during a ten-day period of low-calorie intake and exercise in man. Metabolism 1967: 16: 624-634.

Cartier A, Lemieux I, Almeras N, Tremblay A, Bergeron J, Despres JP. Visceral obesity and plasma glucose-insulin homeostasis: contributions of interleukin- 6 and tumor necrosis factor-alpha in men. J Clin Endocrinol Metab 2008: 93: 1931-1938.
Chaston TB, Dixon JB. Factors associated with percent change in visceral versus subcutaneous abdominal fat during weight loss: findings from a systematic review. Int J Obes (Lond) 2008: 32: 619-628.

Craig CL, Marshall AL, Sjöström M, Bauman AE, Booth ML, Ainsworth BE, Pratt M, Ekelund U, Yngve A, Sallis JF, Oja P. International physical activity questionnaire: 12-country reliability and validity. Med Sci Sports Exerc 2003: 35: 1381-1395.

Despres JP, Lemieux I, Prud'homme D. Treatment of obesity: need to focus on high risk abdominally obese patients. BMJ 2001: 322: 716-720.

Djurhuus CB, Gravholt CH, Nielsen S, Pedersen SB, Moller N, Schmitz O. Additive effects of cortisol and growth hormone on regional and systemic lipolysis in humans. Am J Physiol Endocrinol Metab 2004: 286: E488-E494.

Doyon CY, Brochu M, Messier V, Lavoie ME, Faraj M, Doucet E, Rabasa-Lhoret R, Dionne IJ. Association between abdominal fat (DXA) and its subcomponents (CT scan) before and after weight loss in obese postmenopausal women: a MONET study. J Obes 2011: 2011: 239516.

Drapeau V, Therrien F, Richard D, Tremblay A. Is visceral obesity a physiological adaptation to stress? Panminerva Med 2003: 45: 189-195.

Elia M, Stratton R, Stubbs J. Techniques for the study of energy balance in man. Proc Nutr Soc 2003: 62: 529-537.

Fair AM, Montgomery K. Energy balance, physical activity, and cancer risk. Methods Mol Biol 2009: 472: 57-88.

Farnsworth E, Luscombe ND, Noakes M, Wittert G, Argyiou E, Clifton PM. Effect of a high-protein, energy-restricted diet on body composition, glycemic control, and lipid concentrations in overweight and obese hyperinsulinemic men and women. Am J Clin Nutr 2003: 78: 31-39.
Frayn KN. Calculation of substrate oxidation rates in vivo from gaseous exchange. J Appl Physiol 1983: 55: 628-634.

Friedewald WT, Levy RI, Fredrickson DS. Estimation of the concentration of low-density lipoprotein cholesterol in plasma, without use of the preparative ultracentrifuge. Clin Chem 1972: 18: 499-502.

Garrow JS, Summerbell CD. Meta-analysis: effect of exercise, with or without dieting, on the body composition of overweight subjects. Eur J Clin Nutr 1995: 49: 1-10.

Gibson AL, Holmes JC, Desautels RL, Edmonds LB, Nuudi L. Ability of new octapolar bioimpedance spectroscopy analyzers to predict 4-component-model percentage body fat in Hispanic, black, and white adults. Am J Clin Nutr 2008: 87: 332-338.

Givoni B, Goldman RF. Predicting metabolic energy cost. J Appl Physiol 1971: 30: 429-433.

Gravholt CH, Dall R, Christiansen JS, Moller N, Schmitz O. Preferential stimulation of abdominal subcutaneous lipolysis after prednisolone exposure in humans. Obes Res 2002: 10: 774-781.

Guerra B, Ponce-González JG, Morales-Alamo D, Guadalupe-Grau A, Kiilerich K, Fuentes T, Ringholm S, Biensø RS, Santana A, Lundby C, Pilegaard H, Calbet JA. Leptin signaling in skeletal muscle after bed rest in healthy humans. Eur J Appl Physiol 2014: 114: 345-357.

Kerr SM, Livingstone MB, McCrorie TA, Wallace JM. Endothelial dysfunction associated with obesity and the effect of weight loss interventions. Proc Nutr Soc 2011: 70: 418-425.

Kraschnewski JL, Boan J, Esposito J, Sherwood NE, Lehman EB, Kephart DK, Sciamanna CN. Long-term weight loss maintenance in the United States. Int J Obes (Lond) 2010: 34: 1644-1654.

Krieger JW, Sitren HS, Daniels MJ, Langkamp-Henken B. Effects of variation in protein and carbohydrate 
Fast and efficient reduction of fat mass

intake on body mass and composition during energy restriction: a meta-regression. Am J Clin Nutr 2006: 83: 260-274.

Marniemi J, Vuori I, Kinnunen V, Rahkila P, Vainikka M, Peltonen P. Metabolic changes induced by combined prolonged exercise and low-calorie intake in man. Eur J Appl Physiol Occup Physiol 1984: 53: 121-127.

Matthews DR, Hosker JP, Rudenski AS, Naylor BA, Treacher DF, Turner RC. Homeostasis model assessment: insulin resistance and beta-cell function from fasting plasma glucose and insulin concentrations in man. Diabetologia 1985: 28: 412-419.

McMurray RG, Hackney AC. Interactions of metabolic hormones, adipose tissue and exercise. Sports Med 2005: 35: 393-412.

Miller WC, Koceja DM, Hamilton EJ. A meta-analysis of the past 25 years of weight loss research using diet, exercise or diet plus exercise intervention. Int J Obes Relat Metab Disord 1997: 21: 941-947.

Nieves DJ, Cnop M, Retzlaff B, Walden CE, Brunzell JD, Knopp RH, Kahn SE. The atherogenic lipoprotein profile associated with obesity and insulin resistance is largely attributable to intra-abdominal fat. Diabetes 2003: 52: 172-179.

Pandolf KB, Givoni B, Goldman RF. Predicting energy expenditure with loads while standing or walking very slowly. J Appl Physiol 1977: 43: 577-581.

Pasiakos SM, Cao JJ, Margolis LM, Sauter ER, Whigham LD, McClung JP Rood JC, Carbone JW, Combs GF Jr, Young AJ. Effects of high-protein diets on fat-free mass and muscle protein synthesis following weight loss: a randomized controlled trial. FASEB J 2013: 27: 3837-3847.

Pennings B, Boirie Y, Senden JM, Gijsen AP, Kuipers H, van Loon LJ. Whey protein stimulates postprandial muscle protein accretion more effectively than do casein and casein hydrolysate in older men. Am J Clin Nutr 2011: 93: 997-1005.

Perez-Gomez J, Rodriguez GV, Ara I, Olmedillas H, Chavarren J, Gonzalez-Henriquez JJ, Dorado C, Calbet JA. Role of muscle mass on sprint performance: gender differences? Eur J Appl Physiol 2008: 102: 685-694.

Phillips SM. The science of muscle hypertrophy: making dietary protein count. Proc Nutr Soc 2011: 70: 100-103.

Pou KM, Massaro JM, Hoffmann U, Vasan RS, Maurovich-Horvat P, Larson MG, Keaney JF Jr, Meigs JB, Lipinska I, Kathiresan S, Murabito JM, O’Donnell CJ, Benjamin EJ, Fox CS. Visceral and subcutaneous adipose tissue volumes are cross-sectionally related to markers of inflammation and oxidative stress: the Framingham Heart Study. Circulation 2007: 116: 1234-1241.

Ross R, Dagnone D, Jones PJ, Smith H, Paddags A, Hudson R, Janssen I. Reduction in obesity and related comorbid conditions after diet-induced weight loss or exercise-induced weight loss in men. A randomized, controlled trial. Ann Intern Med 2000: 133: 92-103.

Serrano-Sanchez JA, Delgado-Guerra S, Olmedillas H, Guadalupe-Grau A, Arteaga-Ortiz R, Sanchis-Moysi J, Dorado C, Calbet JA. Adiposity and age explain most of the association between physical activity and fitness in physically active men. PLoS ONE 2010: 5: e13435.

Shaw K, Gennat H, O'Rourke P, Del Mar C. Exercise for overweight or obesity. Cochrane Database Syst Rev 2009: (4): CD003817.

Shpilberg O, Burstein R, Epstein Y, Suessholz A, Getter R, Rubinstein A.
Lipid profile in trained subjects undergoing complete food deprivation combined with prolonged intermittent exercise. Eur J Appl Physiol Occup Physiol 1990: 60: 305-308.

Takata Y, Ansai T, Soh I, Akifusa S, Sonoki K, Fujisawa K, Awano S, Kagiyama S, Hamasaki T, Nakamichi I, Yoshida A, Takehara T. Association between body mass index and mortality in an 80-year-old population. J Am Geriatr Soc 2007: 55: 913-917.

Tang JE, Moore DR, Kujbida GW, Tarnopolsky MA, Phillips SM. Ingestion of whey hydrolysate, casein, or soy protein isolate: effects on mixed muscle protein synthesis at rest and following resistance exercise in young men. J Appl Physiol 2009: 107: 987-992.

Vilsboll T, Christensen M, Junker AE, Knop FK, Gluud LL. Effects of glucagon-like peptide-1 receptor agonists on weight loss: systematic review and meta-analyses of randomised controlled trials. BMJ 2012: 344: d7771.

Westerterp KR. Physical activity and physical activity induced energy expenditure in humans: measurement, determinants, and effects. Front Physiol 2013: 4: 90 .

Willis LH, Slentz CA, Bateman LA, Shields AT, Piner LW, Bales CW, Houmard JA, Kraus WE. Effects of aerobic and/or resistance training on body mass and fat mass in overweight or obese adults. J Appl Physiol 2012: 113: 1831-1837.

World Health Organization (WHO). Fact sheet 311. Geneva: WHO, 2011.

Yang Y, Breen L, Burd NA, Hector AJ, Churchward-Venne TA, Josse AR, Tarnopolsky MA, Phillips SM. Resistance exercise enhances myofibrillar protein synthesis with graded intakes of whey protein in older men. Br J Nutr 2012: 108: 1780-1788. 